\title{
The influence of hydrodynamic processes on zooplankton transport and distributions in the North Western Mediterranean: Estimates from a Lagrangian model
}

\author{
Z.F. Qiu ${ }^{\mathrm{a}, \mathrm{b}}$, A.M. Doglioli a , Z.Y. Hu ${ }^{\mathrm{a}}$, P. Marsaleix ${ }^{\mathrm{c}}$, F. Carlotti ${ }^{\mathrm{a}, *}$ \\ a Laboratoire d'Océanographie Physique et Biogéochimie, Aix Marseille Université, CNRS, UMR 6535, Marseille, France \\ ${ }^{\mathrm{b}}$ Key Laboratory of Ocean Circulation and Waves, Institute of Oceanology, CAS, Qingdao, China \\ ${ }^{\mathrm{c}}$ Laboratoire d'Aérologie, 14 Avenue Edouard Belin, Toulouse, France
}

\begin{abstract}
A Lagrangian module has been developed and coupled with the 3D circulation model Symphonie to study the influence of hydrodynamic processes on zooplankton transport and distributions in the North Western Mediterranean (NWM). Individuals are released every 3 days from March to August 2001 in two initial areas: around the DYFAMED sampling station in the central Ligurian Sea and in the Rhône river plume. Then the individuals are tracked for 40 days either as passive particles or with a simple diel vertical migration (DVM) pattern. The simulations suggest strong seasonal patterns in the distributions of the individuals released around the DYFAMED sampling station. Individuals spread all over the NWM basin after 40 days but different patterns occur depending on the season, the initial depths of release and the capacity of DVM. Offshore-shelf transport only occurs in April and May with particles ending up in the Gulf of Lions (GoL) in low concentrations. In other months, the Northern Current (NC) can be considered as a barrier for particles entering the GoL from the offshore sea. A quarter to a half of passive individuals released in the Rhône river plume remain in the GoL. The rest is transported by the NC towards the Catalan Sea. Applying a simple DVM scheme does not increase the retention of particles on the shelf.
\end{abstract}

\section{Introduction}

Over the past few decades, it has become clear that physical processes are important drivers of population dynamics in the oceans (Miller et al., 1998; Batchelder et al., 2002). Zooplankton organisms are critically dependent on their physical environments but they are not necessarily passive particles (Batchelder et al., 2002; Cianelli et al., 2007; Sentchev and Korotenko, 2007; Carr et al., 2008). They swim vertically which influences their spatio-temporal distributions. At each phase of their development, they have to find prey and avoid predators. At the adult stage they will seek mates and reproduce. Therefore, zooplankton transport in a variety of physical conditions can be considered as the combination of two closely linked processes. The first is zooplankton transport by non-stationary flow fields and the second is the behavioural response of zooplankton, mainly by swimming, to the changes of environmental conditions.

When investigating the relationships between particle distribution and physical processes, researchers often used bio-physical

\footnotetext{
* Corresponding author. Tel.: +33 4910416 44; fax: +33 491041643.

E-mail address: francois.carlotti@univmed.fr (F. Carlotti).
}

models (e.g. Levy et al., 2000; Oschlies, 2002). Lagrangian particle tracking models coupled with hydrodynamic models are particularly efficient tools to examine the role played by various physical processes, to study transport processes over an entire basin and to simulate complex and interactive processes acting at different scales (e.g. Miller et al., 1998; Blanke et al., 1999; Falco et al., 2000; Guizien et al., 2006; Speirs et al., 2006; Lett et al., 2007).

Recent developments of Lagrangian modelling have highlighted the links between physical structures, zooplankton behaviour and marine productivity in regions such as the Benguela ecosystem (Mullon et al., 2003; Lett et al., 2007) or the Georges Bank (Miller et al., 1998). Cianelli et al. (2007) simulated the particle exchange in the Gulf of Lions (GoL) using a Lagrangian approach coupled with a three-dimensional (3D) circulation model. They found that particle distributions are strongly related to the mesoscale and submesoscale hydrodynamic structures on the shelf and to the offshore circulation associated with the Northern Current (NC).

In the North Western Mediterranean (NWM) the large-scale circulation is dominated by the NC that forms in the Ligurian Sea where the Western Corsica Current (WCC) merges with the Eastern Corsica Current (ECC) (Fig. 1, Palomera et al., 2007). From the Ligurian Sea the NC flows along the continental shelf to the Catalan Sea. Sometimes a branch of the NC can intrude into the GoL (Millot 


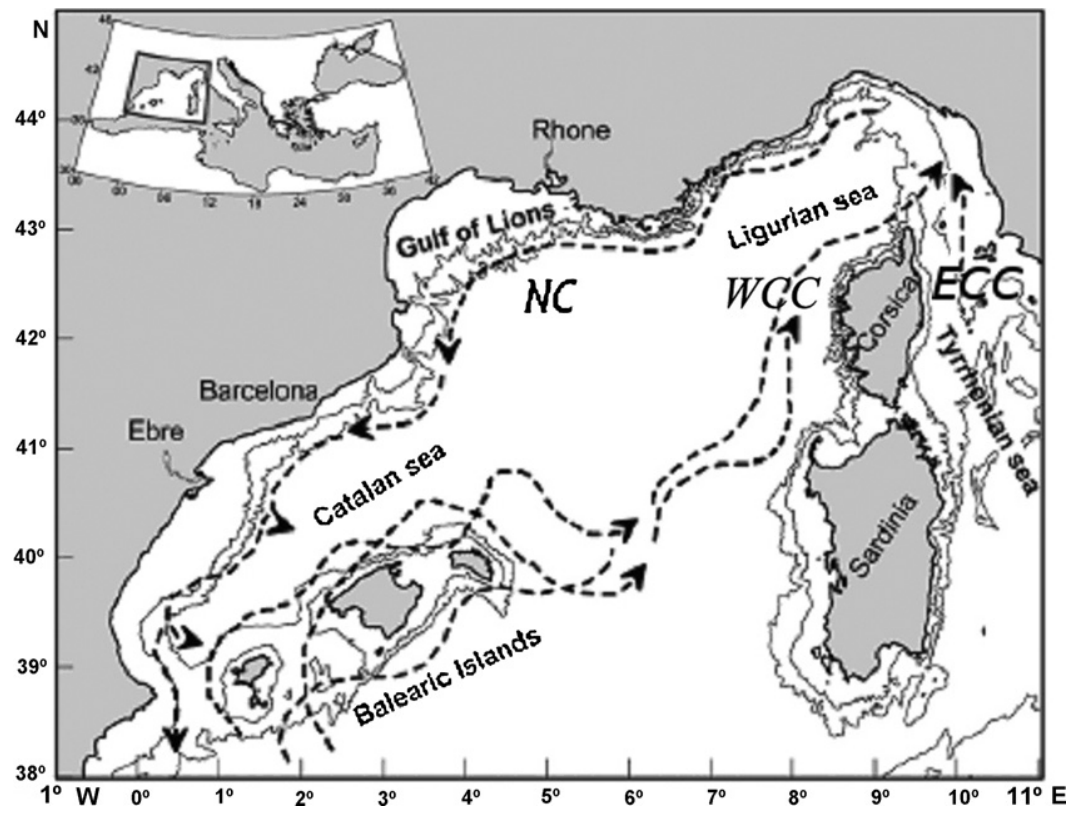

Fig. 1. Major basins and currents in the North Western Mediterranean.

and Wald, 1980; Estournel et al., 2003; Petrenko, 2003; Petrenko et al., 2005). The main hydrodynamic features of the GoL have been previously researched both experimentally and numerically (e.g. Millot, 1999; Andre et al., 2005). The shelf circulation in the GoL is complex due to the combined effects of various forcings, which are mainly the strong winds blowing from the north (Mistral) and from the northwest (Tramontane), the NC, the Rhône river discharges and the complex topography, characterised by several canyons.

The NWM and particularly the GoL, is an interesting area to study the influence of water circulation and estuarine inputs on biological activity and distribution. The NWM sub-basin is one of the most productive areas in the Mediterranean owing to important river discharges from the Rhône and Ebre rivers, strong wind mixing on the shelf and in the open sea, gyres, upwellings and vertical mixing. Production and phytoplankton stock occurring in favourable zones (fronts, whirlwinds, river plumes) induces production and zooplankton stock dominated by Calanus helgolandicus, Centropages typicus, Pseudocalanus and Paracalanus sp. (Champalbert, 1996). Small pelagics (such as sardine and anchovy) and medium size-pelagics (such as mackerel and bonite) are the main contributors to total landings (about 50\%). The GoL is a major spawning area for the small pelagic fish in the NWM (Garcia et al., 1996; Palomera et al., 2007), owing to its relative high primary production over the year (Diaz et al., 2001).

Spatial distribution of zooplankton is a key issue to understand regional functioning of pelagic ecosystem. Spatial differences in zooplankton concentrations may be related to advective and mixing transport as well as local production or predation pressure. In this paper, we use a Lagrangian model to simulate the trajectories of passive particles and vertically migrating organisms. Trajectories of zooplankton individuals of average life-time of 40 days (an average values for copepods, jellyfish, fish larvae) from a detailed physical oceanographic model let us to investigate which part of zooplankton produced on the shelf of the GoL is maintained due to physical retention or concentration mechanisms, and which part is advected outside of the shelf. This is particularly relevant for the fish larvae (anchovy and sardines) produced on the Rhône plume (Palomera, 1991), which can stay on the productive shelf or be washed away in the Catalan Sea. Another major issue is the potential exchange of zooplankton from the Ligurian Sea to the GoL and the Catalan Sea. Jellyfish swarms of Pelagia noctiluca, a small pelagic jellyfish, start off shore in the Ligurian Sea or at the shelf slope in the NWM from March to August (Mariottini et al., 2008) and are advected west ward through the northern current and on the coast depending on surface currents. The third major issue is the advection of plankton larvae of benthic species, such as sponge (Mariani et al., 2006) or sea urchins (Pedrotti, 1993), which can exchange genotypes between different regions of the NWM.

It is well known that zooplankton organisms are not completely passive and may change their vertical position by active swimming or density changes. Diel vertical migration (DVM) is the most common zooplankton swimming behaviour in which organisms reside in surface or near-surface waters at night and in deeper waters during the day. This behaviour enables zooplankton to feed in relatively productive surface waters at night and avoid visual predators during the day (Haney, 1988). The potential effect of DVM on zooplankton transport has been demonstrated by several researchers (Batchelder et al., 2002; Sentchev and Korotenko, 2007; Carr et al., 2008).

Thus our goal is to investigate the influence of advection on zooplankton transport, as well as the combination between advection and DVM, to better evaluate the connections of zooplankton between different regions of the NWM. An outline of the Lagrangian approach is given in the next section. The simulated results, considering zooplankton individuals as passive particles and with active DVM, are presented in Section 3 and discussed in Section 4. In the following text, the term "particles" will be used to describe these zooplankton individuals.

\section{Materials and methods}

\subsection{Hydrodynamic model}

We use the 3D numerical hydrodynamic model Symphonie to determine current fields. A detailed description of the model is given by Marsaleix et al. (2008) and references therein. During last 10 years the model has been successfully used for several studies in the NWM: the NC intrusions on the continental shelf (Auclair et al., 2001; Petrenko et al., 2005; Gatti et al., 2006), wind-forced circulation (Auclair et al., 2003; Estournel et al., 2003; Petrenko et al., 2008) and the Rhône river plume dynamics (Estournel et al., 2001). 


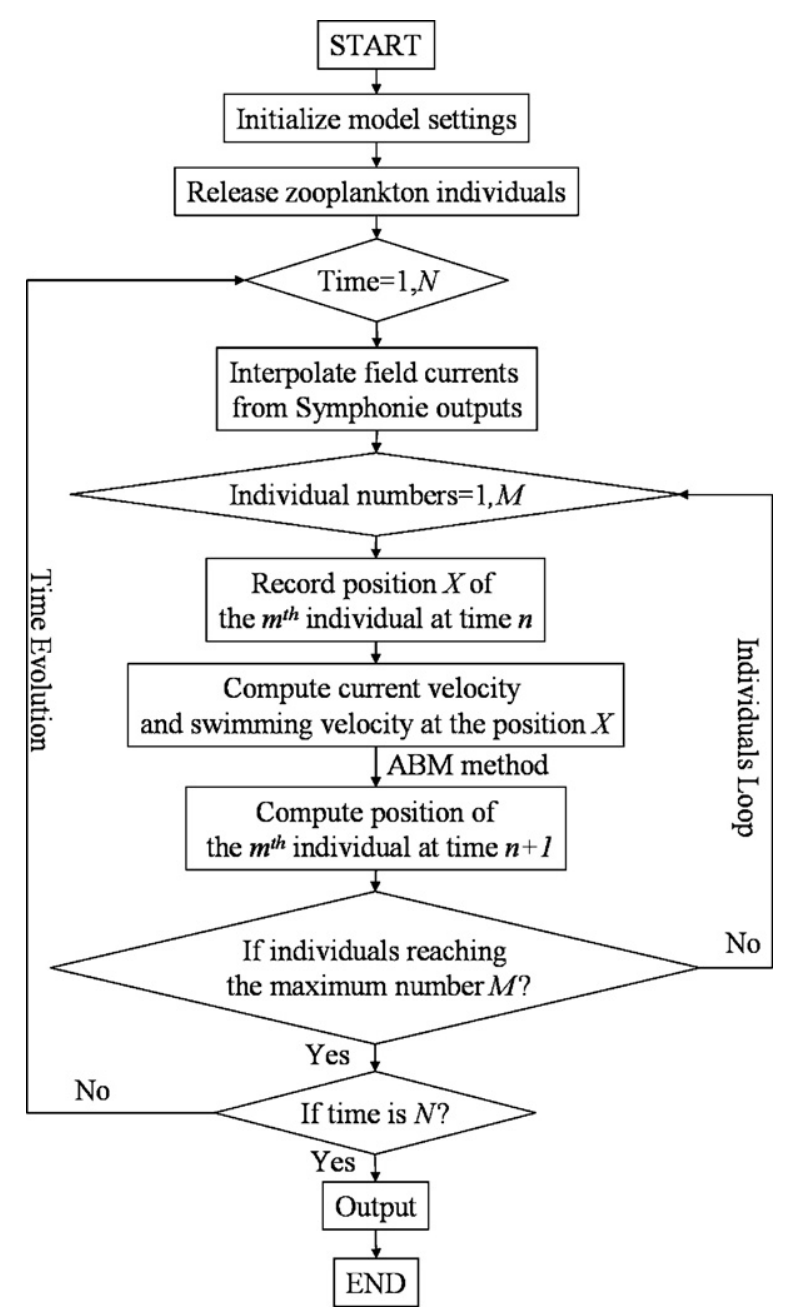

Fig. 2. Flow-chart of the Lagrangian particle tracking model.

In the model, the Arakawa-C grid is used with horizontal mesh of $3 \mathrm{~km}$ and a hybrid $(z-\sigma)$ coordinate system (Estournel et al., 2007 ) with 41 vertical levels. A minimum depth of $3 \mathrm{~m}$ is imposed in nearshore areas. Turbulence closure in the vertical direction is achieved through the scheme proposed by Gaspar et al. (1990). The upwind type advection scheme is described in Hu et al. (2009) and references therein.

The real fresh-water inputs from the Rhône river are provided by the "Compagnie Nationale du Rhône" every day and meteorological forcings are given from the Meteo-France model Aladin at high frequency $(3 \mathrm{~h})$. The restoring terms of the open boundary scheme allow forcing the model with the features of the general circulation given by the regional-scale model MOM.

Modelling results were recently validated by comparison with the satellite measurements by Bouffard et al. (2008) and Hu et al. (2009).

\subsection{Particle tracking model}

We use a Lagrangian particle tracking code based on the ROMS Offline Floats (ROFF, introduced in details by Carr et al., 2008). The brief flow chart is shown in Fig. 2. The Lagrangian particle tracking algorithm is derived from the following vector equation:

$\frac{d x}{d t}=\vec{u}(x, t)$
Here $x$ is the particle location and $\vec{u}$ is the particle velocity at the position $x$. We uses an advanced fourth-order accurate Adams-Bashford-Moulton (ABM hereafter) predictor-corrector scheme to integrate Eq. (1) over time. The advanced ABM method is a predictor-corrector method, combining the Adams-Bashford method (the predictor step, Eq. (2)) and the advanced Adams-Moulton method (the corrector step, Eq. (3)).

$$
\begin{aligned}
\tilde{x}^{n+1}= & x^{n}+\frac{d t}{24}\left[55 \vec{u}\left(x^{n}, t^{n}\right)-59 \vec{u}\left(x^{n-1}, t^{n-1}\right)+37 \vec{u}\left(x^{n-2}, t^{n-2}\right)\right. \\
& \left.-9 \vec{u}\left(x^{n-3}, t^{n-3}\right)\right] \\
x^{n+1}= & \frac{19}{270} \tilde{x}^{n+1}+\frac{251}{270}\left\{x^{n}+\frac{d t}{24}\left[9 \vec{u}\left(\tilde{x}^{n+1}, t^{n+1}\right)+19 \vec{u}\left(x^{n}, t^{n}\right)\right.\right. \\
& \left.\left.-5 \vec{u}\left(x^{n-1}, t^{n-1}\right)+\vec{u}\left(x^{n-2}, t^{n-2}\right)\right]\right\}
\end{aligned}
$$

The right-hand side of Eq. (1) is comprised by a series of stored $3 \mathrm{D}$ velocity fields and zooplankton swimming velocity within their DVM behaviour.

$\vec{u}(x, t)=\vec{u}_{s y m}+\vec{u}_{d v m}$

The item $\vec{u}_{\text {sym }}$ is interpolated in time and space of the daily average velocity fields from the circulation model Symphonie, i.e. the velocity values are linearly interpolated from the eight nearest grid cells.

The item $\vec{u}_{d v m}$ is treated in two ways: (i) zooplankton are considered as passive drifters for which the transport processes are determined uniquely by the velocity fields; (ii) DVM behaviour has been considered as follows: if a particle is above $50 \mathrm{~m}$ at 06:00, it will swim down with the velocity $50 \mathrm{~m} \mathrm{~h}^{-1}$ from 06:00 to 08:00; from 18:00 to 20:00 all particles will swim up from deeper depths to near-surface with the velocity $50 \mathrm{~m} \mathrm{~h}^{-1}$. Otherwise the zooplankton transport processes are only determined by the velocity fields. No limits are fixed for the maximum zooplankton depth. The value $50 \mathrm{~m} \mathrm{~h}^{-1}$ is suggested by field observations (Mauchline, 1998).

We used the $z$ coordinate system in the vertical direction. Moreover, we implemented a particle reflection condition at the model rigid boundaries (the coastal boundaries and the bottom boundaries) while particles leaving the model domain through the open boundaries are assumed to be lost.

After primary simulations, we release particles at two locations to estimate the exchange between the shelf and the offshore sea. The first one is in the Rhône river plume (position R in Fig. 3) and considered as a shelf area. The second one is around the oceanographic sampling station DYFAMED (position D in Fig. 3) and considered as an offshore area. Two hundred particles are released at position $\mathrm{R}$ in a rectangle area of $60 \mathrm{~km} \times 20 \mathrm{~km}$ (the center $4.8^{\circ} \mathrm{E}$, $43.2^{\circ} \mathrm{N}$ ) and at two different depths, with 100 particles at $5 \mathrm{~m}$ and 100 particles at $20 \mathrm{~m}$. Moreover, two hundred particles are released at position $D$ in a square area of $30 \mathrm{~km} \times 30 \mathrm{~km}$ (the center $7.87^{\circ} \mathrm{E}$ $43.42^{\circ} \mathrm{N}$ ) and at two different depths, with 100 particles at $5 \mathrm{~m}$ and 100 particles at $100 \mathrm{~m}$. Here we fix 200 particles, being a good compromise between the need of computer time saving and of assuring a good statistics.

Particles are released at position D and R every 3 days from March 1st to August 31, 2001 and tracked for 40 days. Although the life spans of different species vary considerably, we use 40 days because they would represent one life duration of many species (Mauchline, 1998). Some experiments, such as releasing individuals every 1 day and at each time step and so on, have been performed to test a suitable particle release time scale. The results show that simulations with releasing individuals no longer than every 3 days are suitable for statistic analysis. By considering other factors such 


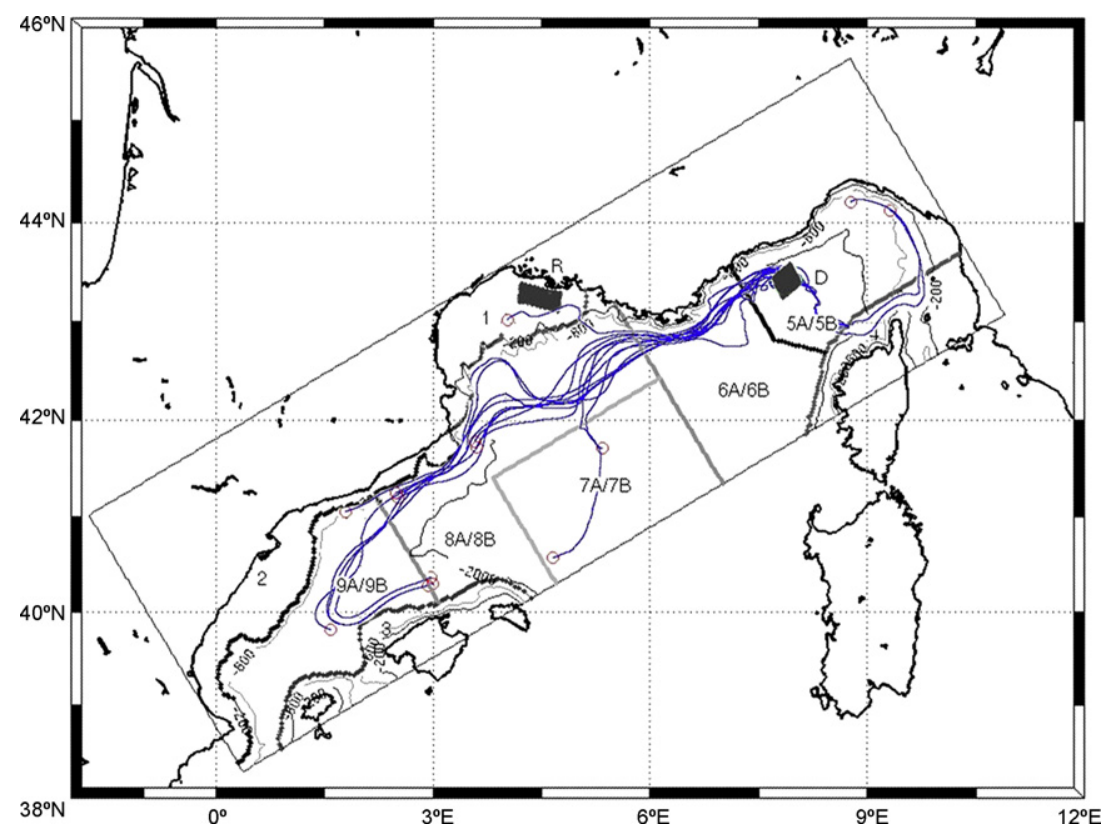

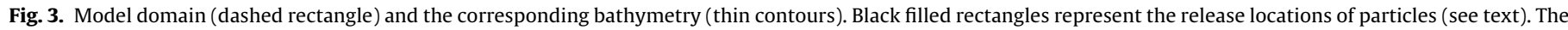

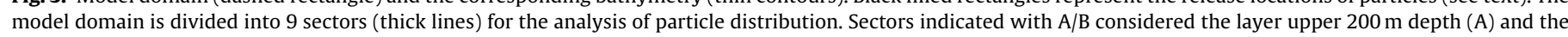

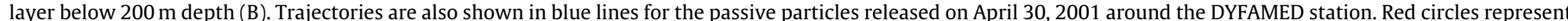

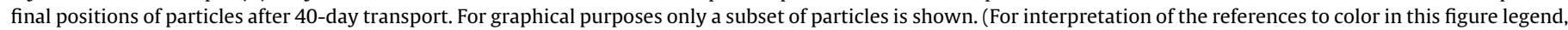
the reader is referred to the web version of the article.)

as computer ability constrains at the same time, we finally choose releasing individuals every 3 days.

After accurate sensitivity tests and considering computing time constraints we decided to run the particle tracking model with a time-step of $300 \mathrm{~s}$.

\subsection{Simulation analysis}

The model domain extends between longitude $1.75^{\circ} \mathrm{W}$ and $10.90^{\circ} \mathrm{E}$ and latitude $38.28^{\circ} \mathrm{N}$ and $45.61^{\circ} \mathrm{N}$ (Fig. 3). In order to classify different zones of the NWM as aggregative or dispersive, we divide the model domain into 9 sectors. Sectors 1 and 2 correspond to shelf areas delimited by the isobath of $200 \mathrm{~m}$ in the GoL and in the Catalan Sea, respectively; sector 3 marks the shelf area around the Balearic islands; sectors 4, 5 and 6 represent the Ligurian Sea (here sectors 5 and 6 represent different ecosystems in the Ligurian Sea); sector 7 bounds the center of the NWM gyre; sector 8 is the shelf slope where the main branch of the NC passes; sector 9 represents the offshore zone in the Catalan Sea.

\section{Results}

\subsection{Fate of passive particles}

Particles are transported almost anywhere in the NWM, highlighting a potential high connectivity between the different regions. As an example of particle transport in simulations without DVM, we show some trajectories of particles released at position D on April 30 (Fig. 3). It is observed that particles are divided into two parts after being released at position D. Following an anticlockwise circulation some particles drift southwards and then eastwards along the WCC. After reaching the area northeast to the Corsica Island, these particles enter the NC then flow northwards along the continental slopes and finally go back at position D. At the end of the simulation, these particles remain in the Ligurian Sea. Similar trajectories in the Ligurian Sea are also observed in the drifter measurements by Poulain (2008). Other particles firstly drift west- wards, then follow the NC along the shelf slope and finally flow into the Catalan Sea. Along the path, some of them leave the NC towards the NWM gyre and the GoL.

The final distribution patterns of particles released at positions $D$ and $R$ are shown in Figs. 4 and 5, respectively. The release locations are also included. The percentages of particles reaching different sectors after 40 days are reported in Tables 1 and 2 . In both the figures and the tables particles released during 1 month have been considered as a whole.

Particles released at position D spread almost anywhere in the NWM but with notable differences depending on the month and the initial depths of release (Fig. 4). In March (Fig. 4A) the majority of particles released at both $5 \mathrm{~m}$ and $100 \mathrm{~m}$ remain in the Ligurian Sea, while a minority of them follow the NC. More of particles released at $100 \mathrm{~m}$ than those released at $5 \mathrm{~m}$ reach the Catalan Sea. In April (Fig. 4B) the situation changes significantly with an increase in the number of particles released at $5 \mathrm{~m}$ reaching the shelf slope and the Catalan Sea. The distribution patterns of particles released at $100 \mathrm{~m}$ in the Catalan Sea are similar to those in March. In May (Fig. 4C) practically all of particles released at both $5 \mathrm{~m}$ and $100 \mathrm{~m}$ reach the Catalan Sea and only a few of them remain in the Ligurian Sea. Compared to the earlier months, a substantial number of particles released at $5 \mathrm{~m}$ enter the GoL. In June (Fig. 4D) few particles end up in the Ligurian Sea, which is similar to that in May. The particles released at $5 \mathrm{~m}$ are divided in two groups, either trapped in the NWM gyre or advected to the Catalan Sea. The particles released at $100 \mathrm{~m}$ are channelled into the $\mathrm{NC}$, along the shelf and in the Catalan Sea. At the east edge of the GoL, some particles released at $100 \mathrm{~m}$ are located in water shallower than $200 \mathrm{~m}$. In July (Fig. 4E) we observe a big difference in final distribution patterns of particles released at both $5 \mathrm{~m}$ and $100 \mathrm{~m}$, in a similar way as that in March. Most of particles released at $100 \mathrm{~m}$ reach the Catalan Sea while those released at $5 \mathrm{~m}$ remain essentially in the Ligurian Sea. Finally, in August (Fig. 4F) the situation is similar to that of July for the particles released at $100 \mathrm{~m}$. However, more particles released at $5 \mathrm{~m}$ spread in the Ligurian Sea and in the NWM gyre. 

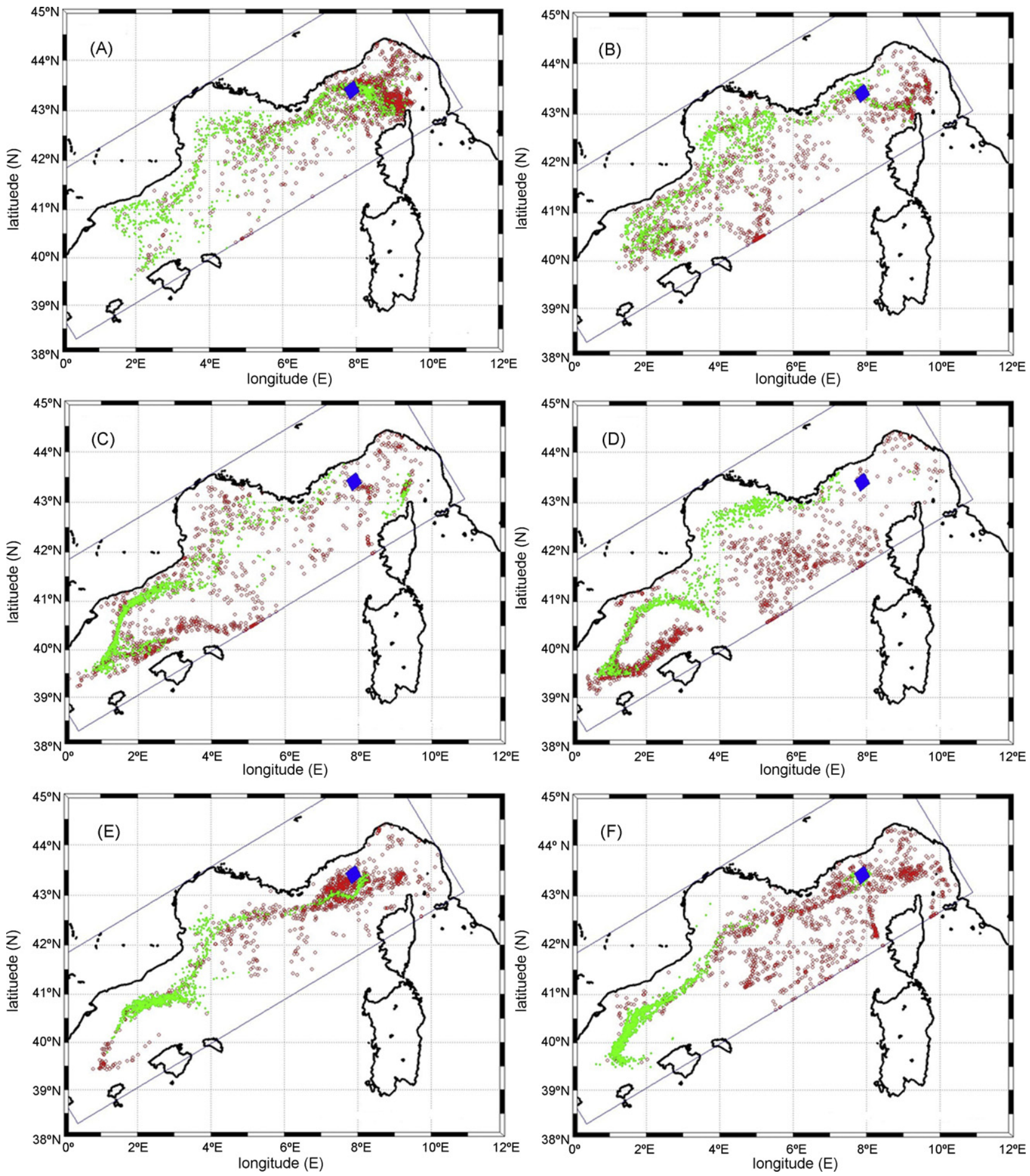

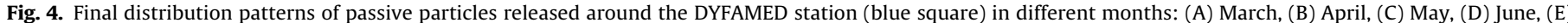

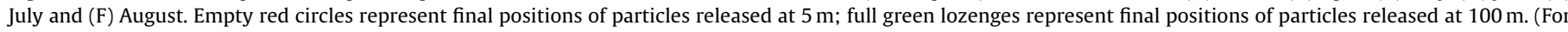
interpretation of the references to color in this figure legend, the reader is referred to the web version of the article.)

Table 1

Percentages of particles reaching different sectors in simulations without DVM (particles released at both $5 \mathrm{~m}$ and $100 \mathrm{~m}$ around the DYFAMED station).

\begin{tabular}{|c|c|c|c|c|c|c|c|c|c|c|c|c|c|c|}
\hline \multirow[t]{2}{*}{ Sector } & \multirow{2}{*}{$\begin{array}{l}\text { GoL } \\
1\end{array}$} & \multicolumn{4}{|c|}{ Catalan Sea } & \multicolumn{5}{|c|}{ Ligurian Sea } & \multicolumn{2}{|c|}{ NWM gyre } & \multicolumn{2}{|c|}{ Shelf slope } \\
\hline & & 2 & 3 & $9 A$ & $9 \mathrm{~B}$ & 4 & $5 A$ & $5 B$ & $6 \mathrm{~A}$ & $6 B$ & $7 \mathrm{~A}$ & 7B & $8 \mathrm{~A}$ & $8 \mathrm{~B}$ \\
\hline March & $\leq 1$ & $\leq 1$ & 1 & 6 & 2 & 10 & 41 & 1 & 12 & $\leq 1$ & 4 & 0 & 21 & 2 \\
\hline April & 2 & $\leq 1$ & $\leq 1$ & 19 & 2 & 4 & 15 & 2 & 5 & 1 & 11 & 0 & 25 & 14 \\
\hline May & 2 & 1 & 2 & 32 & 11 & 3 & 7 & 1 & 5 & 1 & 6 & 0 & 20 & 8 \\
\hline June & 3 & 1 & 3 & 32 & 3 & $\leq 1$ & 3 & $\leq 1$ & 9 & 3 & 13 & 0 & 24 & 7 \\
\hline July & $\leq 1$ & 0 & $\leq 1$ & 20 & $\leq 1$ & 2 & 27 & $\leq 1$ & 17 & 0 & 2 & 0 & 28 & 5 \\
\hline August & $\leq 1$ & $\leq 1$ & $\leq 1$ & 30 & 9 & 3 & 18 & 0 & 14 & 0 & 8 & 0 & 16 & 1 \\
\hline
\end{tabular}



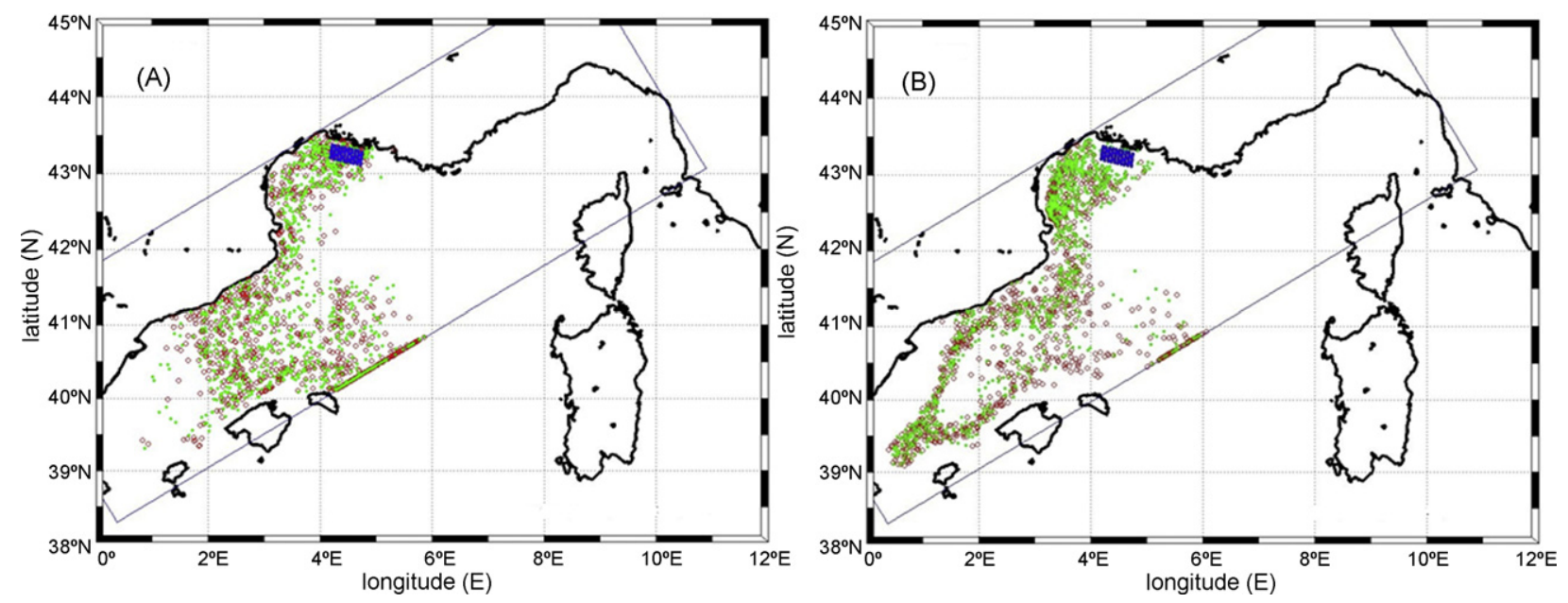

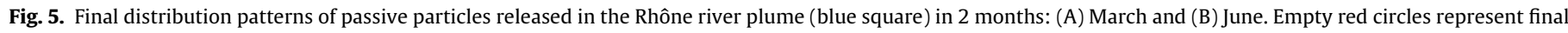

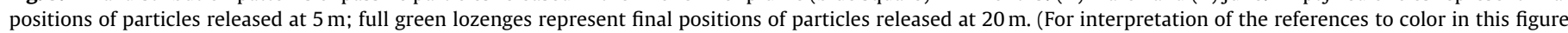
legend, the reader is referred to the web version of the article.)

These results are summarized in Table 1, where percentages of particles reaching different sectors are calculated considering particles released at both $5 \mathrm{~m}$ and $100 \mathrm{~m}$ as a whole. In March over $60 \%$ of particles stay in the Ligurian Sea (sectors 4 to 6 ) while only $9 \%$ of them enter the Catalan Sea (sectors 2, 3 and 9). Most particles are concentrated in the superficial layer of the eastern Ligurian Sea ( $41 \%$ in sector $5 \mathrm{~A}$ ). In April the maximum particle percentage of $39 \%$ is found on the shelf slope (sector 8). In May and June the maximum percentages of particles (43\% and 35\%, respectively) are observed in the Catalan Sea. In July about $47 \%$ of particles remain in the Ligurian Sea and $33 \%$ of them are located on the shelf slope while $20 \%$ reach the Catalan Sea. Finally, in August the maximum particle percentage of $39 \%$ is found in the Catalan Sea. Furthermore, Table 1 shows that only a few of particles released at position D enter the GoL and finally stay there (the maximum of $3 \%$ in June).

Particles released at position $\mathrm{R}$ spread mainly southwestwards and none are able to reach the Ligurian Sea (Fig. 5). Monthly differences in final distribution patterns of particles are observed while the initial depths of release $(5 \mathrm{~m}$ and $20 \mathrm{~m}$ ) do not seem to affect the final distribution patterns. Two main distribution patterns of particles might be distinguished in the whole set of simulations (from March to August). In the first case (March and April, Fig. 5A), particles out of the GoL mostly scatter in the northeastern Catalan Sea and in the western NWM gyre. A certain number of particles reach the southern open boundary. In the second case (from May to August, Fig. 5B), the situation changes with particles out of the GoL being mainly located in the path of the NC. A decrease in the number of particles reaching the southern open boundary is also observed. In both cases a large number of particles remain in the GoL (Fig. 5).

Differences in final distribution patterns of particles according to the month of release are summarized in Table 2. In March about $24 \%$ of particles remain in the GoL and $16 \%$ in the NWM gyre. Most particles are located on the shelf slope with the percentage of $38 \%$. In April and May an increase in the number of particles is observed in the GoL and the total percentages of particles are $47 \%$ and $56 \%$, respectively. On the other hand, less than $15 \%$ of particles reach the Catalan Sea. The percentage of particles in the NWM gyre is $12 \%$ in April and only 2\% in May. From June to August the percentages of particles in the GoL and on the shelf slope do not change (around $35 \%$ and $25 \%$, respectively). More particles scatter in the NWM gyre in June (7\%) than in July and August (5\% and 1\%, respectively), but less in the Catalan Sea (32\% compared to $36 \%$ and $40 \%$, respectively).

\subsection{Fate of particles with DVM}

The final distribution patterns of particles released at positions $D$ and $R$ are shown in Figs. 6 and 7, respectively. For the sake of simplicity we show final distribution patterns of particles for several months representative of the whole set of simulations (from March to August). We calculate differences between percentages of particles reaching combined regions (as introduced in Section 2.3) in simulations with DVM and those without DVM (Tables 3 and 4). The tables also show the percentages of particles reaching combined regions in simulations with DVM.

Regarding particles released at position $\mathrm{D}$, differences in final distribution patterns are observed depending on the month and the initial depths of release. In March (Fig. 6A) a large number of particles concentrate in the Ligurian Sea. Other particles follow the NC and a few of them reach the Catalan Sea. Differences in final distribution patterns of particles for both initial depths of release are small. In June (Fig. 6B) very few of particles released at both $5 \mathrm{~m}$ and $100 \mathrm{~m}$ remain in the Ligurian Sea. Most of particles released at $100 \mathrm{~m}$ accumulate in the path of the NC along the shelf slope. The majority of particles released at $5 \mathrm{~m}$ are channelled into the path of the NC in the Catalan Sea. In August (Fig. 6C) some particles released

Table 2

Percentages of particles reaching different sectors in simulations without DVM (particles released at both $5 \mathrm{~m}$ and $20 \mathrm{~m}$ in the Rhône river plume).

\begin{tabular}{|c|c|c|c|c|c|c|c|c|c|c|c|c|c|c|}
\hline \multirow[t]{2}{*}{ Sector } & \multirow{2}{*}{$\begin{array}{l}\text { GoL } \\
1\end{array}$} & \multicolumn{4}{|c|}{ Catalan Sea } & \multicolumn{5}{|c|}{ Ligurian Sea } & \multicolumn{2}{|c|}{ NWM gyre } & \multicolumn{2}{|c|}{ Shelf slope } \\
\hline & & 2 & 3 & $9 A$ & $9 \mathrm{9B}$ & 4 & $5 \mathrm{~A}$ & $5 B$ & $6 \mathrm{~A}$ & $\overline{6 B}$ & $7 \mathrm{~A}$ & 7B & $8 \mathrm{~A}$ & $8 \mathrm{~B}$ \\
\hline March & 24 & 3 & 5 & 14 & $\leq 1$ & 0 & 0 & 0 & 0 & 0 & 16 & 0 & 38 & $\leq 1$ \\
\hline April & 47 & 1 & 1 & 12 & $\leq 1$ & 0 & 0 & 0 & 0 & 0 & 12 & 0 & 26 & 0 \\
\hline May & 56 & 4 & $\leq 1$ & 10 & 0 & 0 & 0 & 0 & 0 & 0 & 2 & 0 & 29 & 0 \\
\hline June & 35 & 2 & 2 & 28 & 0 & 0 & 0 & 0 & 0 & 0 & 7 & 0 & 27 & 0 \\
\hline July & 34 & 1 & 3 & 32 & 0 & 0 & 0 & 0 & 0 & 0 & 5 & 0 & 25 & 0 \\
\hline August & 36 & 7 & 3 & 30 & 0 & 0 & 0 & 0 & 0 & 0 & $\leq 1$ & 0 & 23 & 0 \\
\hline
\end{tabular}



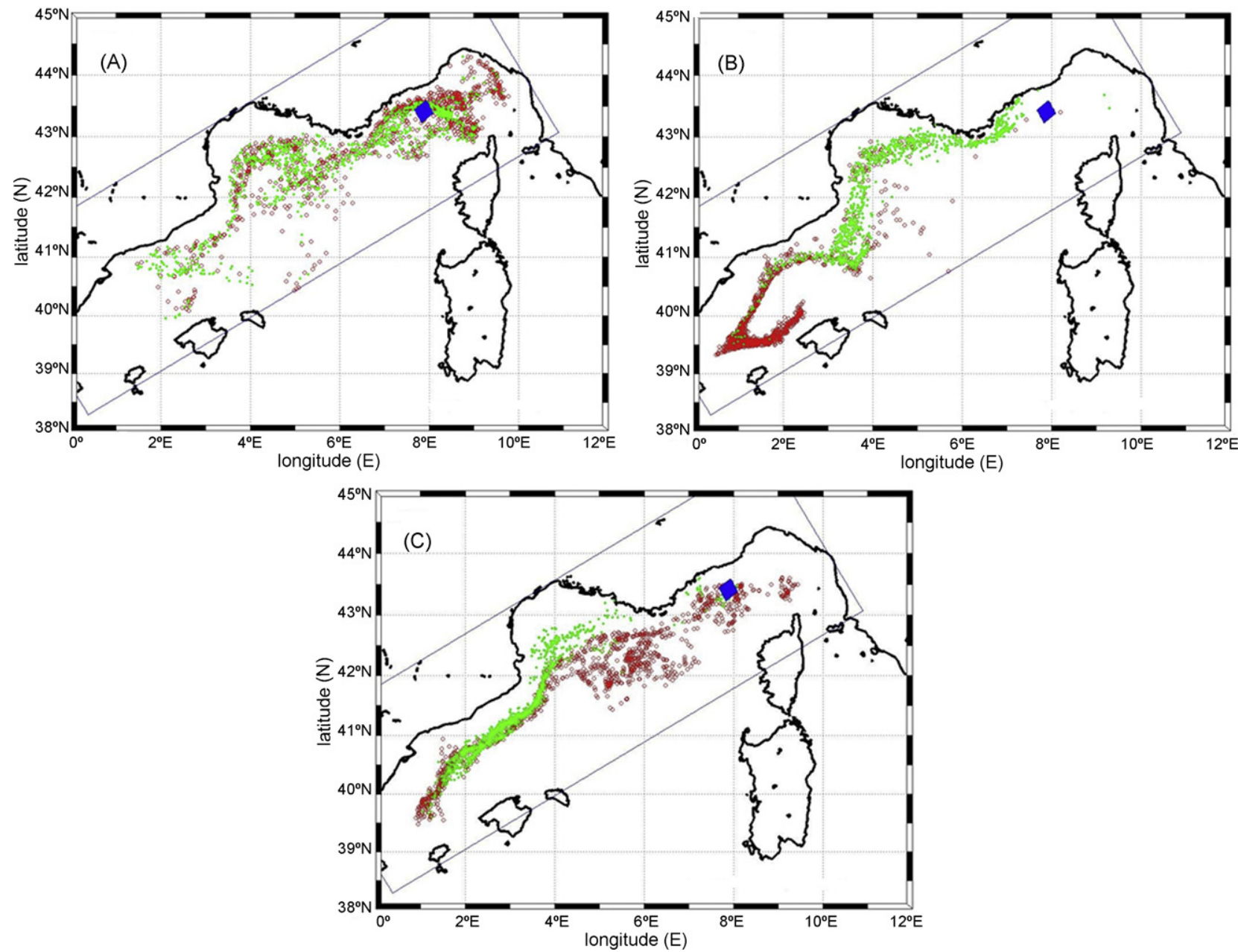

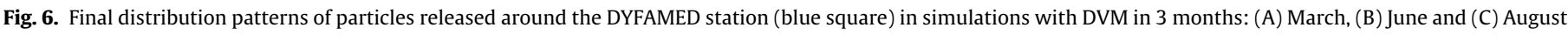

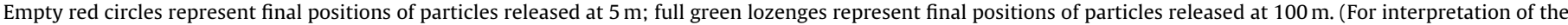
references to color in this figure legend, the reader is referred to the web version of the article.)

Table 3

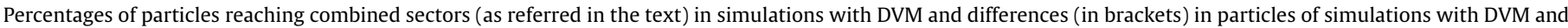
those without DVM (particles released at both $5 \mathrm{~m}$ and $20 \mathrm{~m}$ around the DYFAMED station).

\begin{tabular}{|c|c|c|c|c|c|}
\hline Sector & $\begin{array}{l}\text { GoL } \\
(1)\end{array}$ & $\begin{array}{l}\text { Catalan Sea } \\
(2,3,9)\end{array}$ & $\begin{array}{l}\text { Ligurian Sea } \\
(4,5,6)\end{array}$ & $\begin{array}{l}\text { NWM gyre } \\
\text { (7) }\end{array}$ & $\begin{array}{l}\text { Shelf slope } \\
(8)\end{array}$ \\
\hline March & $\leq 1(0)$ & $4(-4)$ & $59(-6)$ & $3(-1)$ & $33(+10)$ \\
\hline April & $2(0)$ & $21(0)$ & $23(-4)$ & $2(-9)$ & $52(+13)$ \\
\hline May & $\leq 1(-1)$ & $42(-4)$ & $15(-2)$ & $2(-4)$ & $40(+12)$ \\
\hline June & $2(-1)$ & $43(+4)$ & $11(-4)$ & $1(-12)$ & $41(+10)$ \\
\hline July & $\leq 1(0)$ & $10(-11)$ & $41(-4)$ & $2(0)$ & $47(+14)$ \\
\hline August & $\leq 1(0)$ & $27(-12)$ & $17(-18)$ & $7(-1)$ & $48(+31)$ \\
\hline
\end{tabular}

Table 4

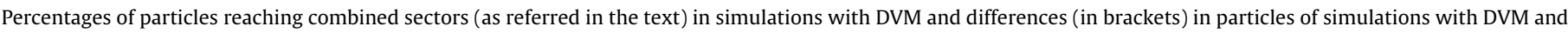
those without DVM (particles released at both $5 \mathrm{~m}$ and $20 \mathrm{~m}$ in the Rhône river plume).

\begin{tabular}{|c|c|c|c|c|c|}
\hline Sector & $\begin{array}{l}\text { GoL } \\
(1)\end{array}$ & $\begin{array}{l}\text { Catalan Sea } \\
(2,3,9)\end{array}$ & $\begin{array}{l}\text { Ligurian Sea } \\
(4,5,6)\end{array}$ & $\begin{array}{l}\text { NWM gyre } \\
\text { (7) }\end{array}$ & $\begin{array}{l}\text { Shelf slope } \\
\text { (8) }\end{array}$ \\
\hline March & $10(-14)$ & $43(+20)$ & $0(0)$ & $\leq 1(-15)$ & $46(+8)$ \\
\hline April & $32(-15)$ & $39(+24)$ & $0(0)$ & $6(-6)$ & $22(-3)$ \\
\hline May & $42(-14)$ & $6(-8)$ & $0(0)$ & $\leq 1(-1)$ & $51(+23)$ \\
\hline June & $16(-19)$ & $36(+5)$ & $0(0)$ & $0(-7)$ & $47(+21)$ \\
\hline July & $23(-11)$ & $28(-8)$ & $0(0)$ & $\leq 1(-5)$ & $49(+24)$ \\
\hline August & $20(-16)$ & $40(0)$ & $0(0)$ & $0(-1)$ & $39(+17)$ \\
\hline
\end{tabular}



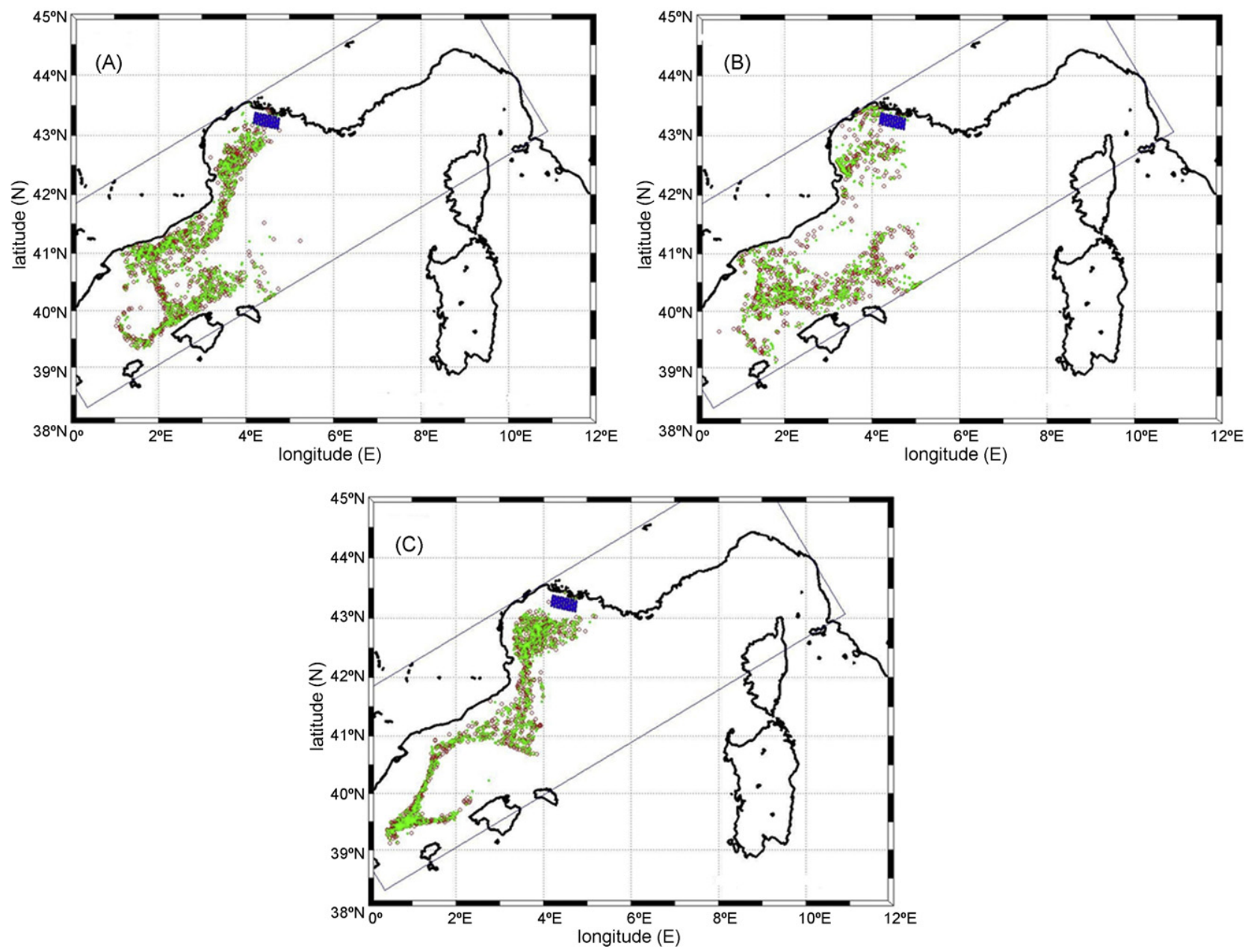

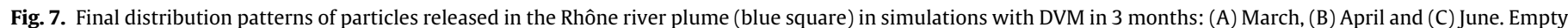

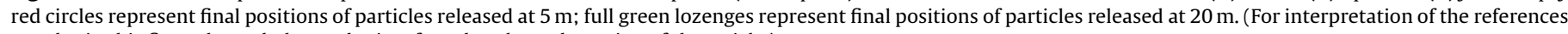
to color in this figure legend, the reader is referred to the web version of the article.)

at $5 \mathrm{~m}$ are located in the Ligurian Sea and the NWM gyre. Moreover, some particles released at $5 \mathrm{~m}$ and the majority of particles released at $100 \mathrm{~m}$ end up in the path of the NC along the shelf slope and in the Catalan Sea.

Compared to simulations without DVM(Fig. 4), simulations with DVM show less spreading of particles, particularly for the particles released at $5 \mathrm{~m}$. In Table 3 we can observe an increase in the number of particles on the shelf slope in simulations with DVM compared to those without DVM, whereas other regions lose particles except for the Catalan Sea in June.

Regarding particles released at position $\mathrm{R}$, monthly differences in final distribution patterns are observed, whereas the effect of initial depths of release could be neglected. In March (Fig. 7A) some particles are located in the central and southwestern GoL. Some particles reach the Catalan Sea and two different distribution patterns appear. These patterns are separated appropriately along the latitude $40.5^{\circ} \mathrm{N}$ and a connection for the two patterns is observed in the area north to the Mallorca Island. In April (Fig. 7B) some particles are located in the northeastern and southwestern GoL. Other particles mainly accumulate in the central and southern Catalan Sea. In June (Fig. 7C) particle distribution patterns in the GoL are similar to those in March, but more particles out of the GoL concentrate in the path of the NC.

Compared to simulations without DVM (Fig. 5), simulations with DVM decrease the spread of the final distribution patterns and the number of particles reaching the open boundary. In general
(Table 4), simulations with DVM increase the number of particles in the Catalan Sea (except in May and July) and on the shelf slope (except in April), but decrease them in the GoL and in the NWM gyre. No changes are observed in the Ligurian Sea.

\section{Discussion}

\subsection{Fate of particles released around the DYFAMED station}

To discuss the relationship between particle distribution and currents, we plot the monthly average circulation patterns in March, June and August from the circulation model Symphonie (Fig. 8).

In March (Fig. 8A, B) the WCC, the ECC and the NC form a cyclonic circulation in the Ligurian Sea. In the particle release area and the central Ligurian Sea, low velocity currents are observed. After being released, most particles are advected by the low velocity currents towards the central Ligurian Sea. Some of them are advected in the cyclonic circulation. That explains why over $60 \%$ of particles stay in the Ligurian Sea, especially $10 \%$ in sector 4 , which is the largest percentage in all months. In the final distribution patterns of particles, more particles released at $5 \mathrm{~m}$ remain in the Ligurian Sea than those released at $100 \mathrm{~m}$. One reason is that one southeast branch of the $\mathrm{NC}$ is observed west of $8^{\circ} \mathrm{E}$ at $5 \mathrm{~m}$ instead of at $100 \mathrm{~m}$. This branch carries particles back to the Ligurian Sea. This is also a reason that more particles released at $100 \mathrm{~m}$ reach the Catalan 

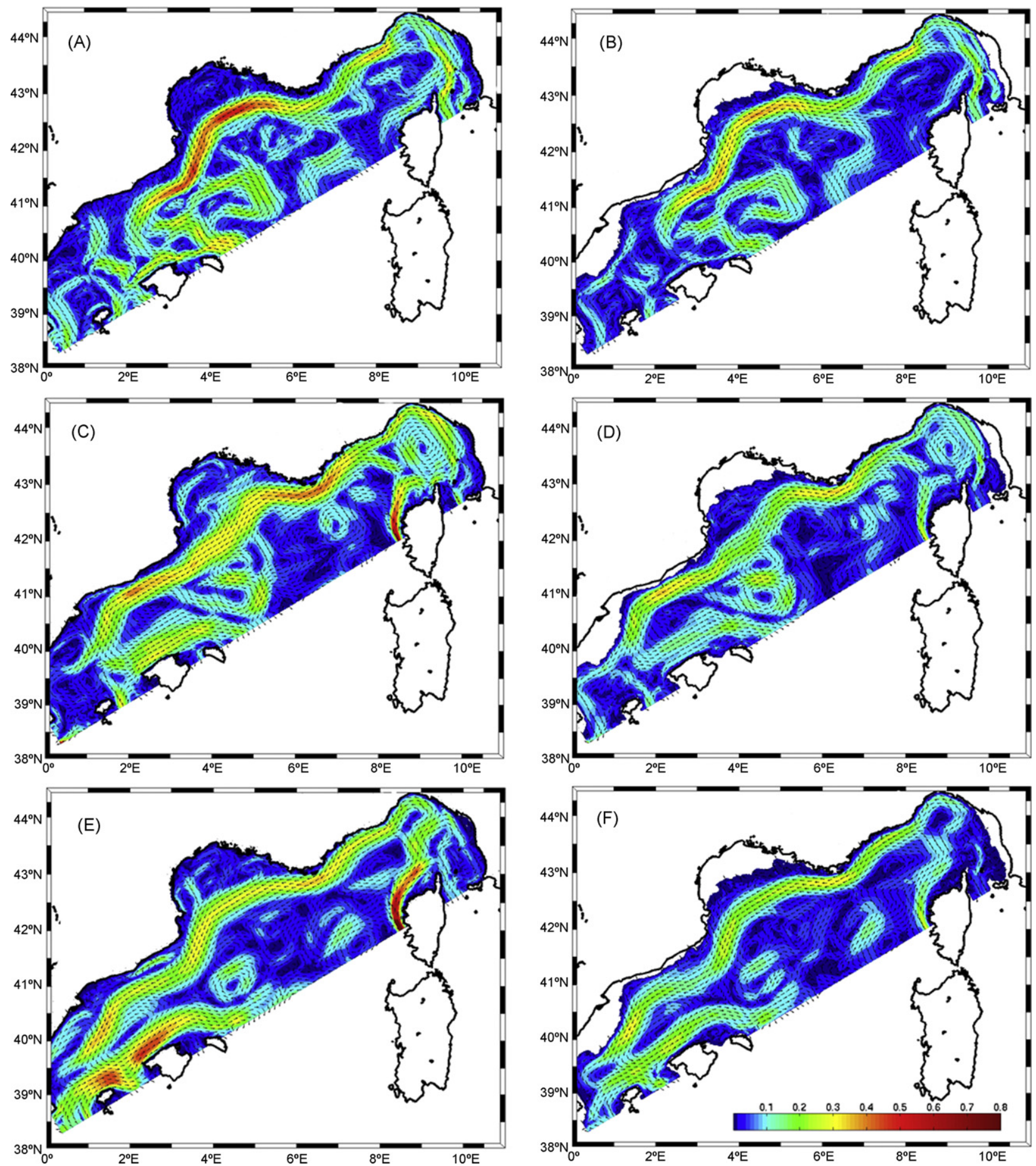

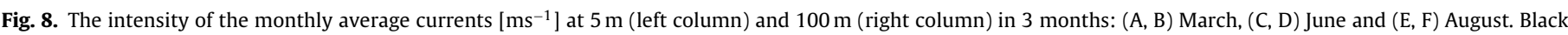
arrows represent directions of currents.

Sea than those released at $5 \mathrm{~m}$. Furthermore, it explains why more particles released at $5 \mathrm{~m}$ reach the shelf slope and the Catalan Sea in simulations with DVM than those without DVM.

In June (Fig. 8C, D) a northwestward current is observed at position D. This current drives particles directly in the NC and few particles remain in the Ligurian Sea. This explains why lower than $5 \%$ of particles remain in sectors 4 and 5 . Furthermore, the NC velocity is higher at $5 \mathrm{~m}$ than that at $100 \mathrm{~m}$. Consequently the particles released at $5 \mathrm{~m}$ drift further than those released at $100 \mathrm{~m}$ when reaching the Catalan Sea. The variability of surface currents explains why some particles released at $5 \mathrm{~m}$ flow into the NWM gyre. In sim- ulations with DVM, a large decrease in spread is observed for the final distribution patterns of the particles released at $5 \mathrm{~m}$, especially in the NWM gyre, because currents in deeper water prevent particles from escaping from the NC.

In August (Fig. 8E, F) a northwestward current is still observed at $100 \mathrm{~m}$ while it does not exist at $5 \mathrm{~m}$. This pattern explains why the particles released at $5 \mathrm{~m}$ spread in the Ligurian Sea while those released at $100 \mathrm{~m}$ are channelled into the NC and quickly transported out of the Ligurian Sea. It also explains why a decrease in the number of particles released at $5 \mathrm{~m}$ is observed in the Ligurian Sea and the NWM gyre in simulations with DVM, compared to those 
without DVM. Furthermore, it is the reason why the percentages of particles in the Ligurian Sea are lower than those in March and higher than those in June.

Rubio et al. (2009) showed that drifting buoys launched at the south-eastern part of the GOL and tracked by the ARGOS satellite system in the NWM Sea during summer 2005 were never entering on the shelf of the GOL but drifted in the NC over the shelf slope, however temporary trapped in mesoscale structures associated with the NC. Our simulations in June, July and August are consistent with their observations and simulations.

The NC plays a clear role as vector from the Ligurian Sea to the Catalan Sea. According to several campaigns performed in the NWM (Alberola et al., 1995; Petrenko, 2003), the NC flux varies throughout the year, with a maximum flux $1.5-2 \mathrm{~Sv}$ (down to $700 \mathrm{dbar}$ ) during the winter and spring seasons (roughly from December to May). The NC velocity is higher in June than that in August (Fig. 8). Thus particles released in June flow faster and further accordingly, which is shown in the final distribution patterns of particles in the Catalan Sea. In addition, the NC flows southwards in the area north to the Mallorca Island (east of $2^{\circ} \mathrm{E}$ ) in March and flows southwestwards further along the continental slope of the Catalan Sea (up to $0.5^{\circ} \mathrm{E}$ ) in June and August (Fig. 8). This explains why more particles are located in the northeastern Catalan Sea in March than those in June and August.

Under specific wind and stratification conditions, surface waters of the NC tend to penetrate onto the shelf at the eastern entrance of the GoL (Millot and Wald, 1980; Auclair et al., 2003; Echevin et al., 2003; Petrenko, 2003; Petrenko et al., 2005). Consequently, the penetration will carry particles onto the shelf. However in our simulations, offshore-shelf transport is rare and the particles end up in the GoL in low concentrations. Most of the time, the NC flows southwestwards along the shelf break delimiting the GoL and acts as a barrier which separates the shelf circulation from the regional circulation. Moreover, even though particles move occasionally into the GoL advected by the penetrating branch of the NC, some of them will be washed out of the GoL by the southwestern branch of currents in the Rhône river plume.

Different percentages of particles reaching combined regions are shown in the previous sections for particles released around the DYFAMED station between simulations with DVM and those without DVM. The differences are relate to combined influence of currents and swimming behaviours. Swimming behaviours in simulations with DVM deduce a different vertical distribution pattern of particles from those without DVM. Despite the effect of vertical currents one particle released at $5 \mathrm{~m}$ will remain in the depth of $5 \mathrm{~m}$ on a whole day. However when swimming behaviours considered the particle will stay at the surface and in the depth about $100 \mathrm{~m}$ almost half a day, respectively. The situations for simulations with particles released at $100 \mathrm{~m}$ may be deduced by analogy. As shown in Fig. 8 currents at $5 \mathrm{~m}$ differ from those at $100 \mathrm{~m}$, stronger but more divergent at the surface than in the deeper layer. Our simulations with DVM show that some particles will reduce durations in the currents at the surface and increase those in deeper layer compared to those without DVM. That is a reason to explain the results shown in Table 3. An increase in the number of particles on the shelf slope is observed, whereas other regions lose particles except for the Catalan Sea in June.

\subsection{Fate of particles released in the Rhône river plume}

A quarter to a half of particles released at position $\mathrm{R}$ remain in the GoL in simulations without DVM. One reason is that the shelf circulation is weak in the main areas of the GoL (Fig. 8). Thus the transport speed of particles is small. Another reason is due to gyres and eddies on the shelf (Hu et al., 2009). When particles enter in, they are prevented escaping from the GoL.
Two different distribution patterns of particles out of the GoL are due to the variability of the NC. The path of the NC changes in the Catalan Sea in different months, as discussed in the previous section. In several simulations, particles were trapped in the Balearic Current and then aggregated in the associated North Balearic Front. In their application to the transport in the NWM region, Mancho et al. (2008) identified the North Balearic Front as a Lagrangian barrier. The region has been identified as a key spawning are for the bluefin tuna, as well as a feeding area for anchovy and sardines (Tugores et al., in press).

In our simulations, particles can drift out to the offshore sea in all months all along the south boundary of the GoL (data not shown). On the contrary, an offshore-shelf particle exchange only appears when the NC penetrates into the GoL under specific wind and stratification conditions (Auclair et al., 2003; Petrenko, 2003; Petrenko et al., 2005). Thus our simulations show that physical processes favour the shelf-offshore particle exchange.

DVM behaviour reduces transport of particles away from the regions where there are offshore currents at the surface and onshore currents at deeper depths (Botsford et al., 1994; Batchelder et al., 2002). This effect of DVM has been observed in the upwelling regions and river plumes of the GoL (data not shown). However, in most of our simulations, DVM behaviour does not increase the number of particles remaining in the GoL because of complex currents on the shelf. The upwelling phenomenon of the GoL displays a very large spatio-temporal variability due to the coastline geometry and the high variability of winds. Andre et al. (2005) found that the upwellings along the northeastern coasts of the GoL and south of Cape d'Agde are wind-driven, the former by the Mistral and the latter by the Tramontane.

Moreover, currents in the GoL vary vertically owing to the combined effects of various forcings. For instance, the hydrological structures in the central GoL are complex, with the influence of the Rhône river's fresh-water plume in the first $40 \mathrm{~m}$ of the water column and, closer to the bottom, with the confrontations of downwelled coastal cold water and upwelled warmer and saltier slope water (Estournel et al., 2003). The current direction changes largely in depth, inducing an increase in the number of particles either remaining in or escaping from the GoL. Our results show that most of the simulations with DVM do not favour an increase in the number of particles remaining in the GoL.

Compared to simulations without DVM, simulations with DVM induce a large increase in the number of particles in the Catalan Sea (in March and April) and on the shelf slope (from May to August), as described before. One reason is that the NC velocity is higher in March and April than that from May to August. Another reason could be that DVM behaviour reduces particles escaping from the NC. In March (Fig. 8A, B) an anti-cyclonic circulation is located close to the NC path in sector 7 (between $4^{\circ} \mathrm{E}$ and $6^{\circ} \mathrm{E}$ ). When tracked passively, about $16 \%$ of particles flow in this circulation to the NWM gyre from the NC. When tracked with DVM, most of these particles continue to flow in the NC and enter the Catalan Sea. The same situation occurs in June.

\subsection{Ecological relevance}

The objective of our study was to quantify and to model zooplankton transport and Lagrangian modelling can be an effective way to investigate dynamic transport patterns of invertebrates. However we have no way to validate such model, because little is known about zooplankton (including ichthyoplankton) distribution and transport in the NWM, data being very scarce. Agostini and Bakun (2002) noted as final conclusion for the understanding of anchovy stock dynamics in the NWM that "fully testing these ideas would require a greater sampling effort than heretofore undertaken, so as to be able to assemble and make available basic 
information on the spatial distribution of spawning. This information is surprisingly lacking for such an ocean area which is bordered by a number of relatively affluent and technologically advanced states that have very important interests in marine resource management and marine ecosystem conservation." Our simulations show that any study of plankton dispersal for organisms of life duration larger than the week should be addressed at the regional scale.

It is clear that such "transport studies" will probably increase in the next decade using satellite-tracked drifters, and by guiding the vertical position of the drifter might help to mimic zooplankton transport. Several key issues in the NWM related to fisheries, jelly fish swarms, and ecosystem functioning requires such integrated approaches.

\section{Conclusions}

We have developed a Lagrangian tool to simulate the transport and distributions of particles coupled with the 3D circulation model Symphonie. The particles could be zooplankton, sediment or other passive suspended matter. A primary DVM scheme has been considered and successfully used for zooplankton. The Lagrangian tool has been used to estimate the influence of hydrodynamic processes on zooplankton transport and distributions in the NWM.

Our results suggest that the particle transport and distributions are strongly related to the hydrodynamic structures on the shelf and the offshore circulations associated with the NC. On the regional scale, particles spread almost anywhere in the NWM after being transported for 40 days, when released around the DYFAMED station. In the spring and summer conditions, the current fields in the NWM favour a shelf-offshore particle exchange, whilst offshore-shelf transport is nearly inhibited. The NC can be considered as a barrier for particles entering the GoL from the offshore sea. Most of particles released in the Rhône river plume either stay in the GoL or end up in the Catalan Sea.

The biological processes associated with particles have been considered using a simple DVM scheme. Our DVM scheme is overly simple and does not increase the number of particles remaining on the shelf. As a next step, we will include more biological processes during the life time of particles, such as growth, development and associated changes in swimming velocity (see Carlotti and Wolf, 1998, as an example). In order to do this, we will consider the phytoplankton and micro-zooplankton distributions in the NWM and couple our Lagrangian model with the biogeochemical model Eco3M (Baklouti et al., 2006).

\section{Acknowledgements}

We thank Dr. Capet for kindly providing the ROFF codes. We also thank the two anonymous reviewers for their very constructive comments and Rose Campbell for her help improving the grammar of our manuscript. The author Qiu Z.F. is supported by a 2 years CNRS post-doc grant (National Center for Scientific Research). The work is also a contribution to the project LAPLACE (CNRS programme EC2CO) and the Fund for Creative Research Groups by NSFC (40821004).

\section{References}

Agostini, V.N., Bakun, A., 2002. 'Ocean triads' in the Mediterranean Sea: physical mechanisms potentially structuring reproductive habitat suitability (with example application to European anchovy, Engraulis encrasicolus). Fish. Oceanogr. 11 (3), 129-142.

Alberola, C., Millot, C., Font, J., 1995. On the seasonal and mesoscale variabilities of the Northern Current during the PRIMO-0 experiment in the western Mediterranean Sea. Ocean. Acta 18 (2), 163-192.

Andre, G., Garreau, P., Garnier, V., Fraunie, P., 2005. Modelled variability of the sea surface circulation in the North-western Mediterranean Sea and in the Gulf of Lions. Ocean. Dyn. 55, 294-308.
Auclair, F., Marsaleix, P., Estournel, C., 2001. The penetration of the northern current over the Gulf of Lion (western Mediterranean Sea) as a downscaling problem. Ocean. Acta 24, 529-544.

Auclair, F., Marsaleix, P., De Mey, P., 2003. Space-time structure and dynamics of the forecast error in a coastal circulation model of the Gulf of Lions. Dyn. Atmos. Oceans 36, 309-346.

Baklouti, M., Faure, V., Pawlowski, L., Sciandra, A., 2006. Investigation and sensitivity analysis of a mechanistic phytoplankton model implemented in a new modular numerical tool (Eco3 M) dedicated to biogeochemical modelling. Progr. Oceanogr. 71, 34-58.

Batchelder, H., Edwards, C., Powell, T., 2002. Individual-based models of copepod population in coastal upwelling regions: implications of physiologically influenced diel vertical migration on demographic success and nearshore retention. Progr. Oceanogr. 53, 307-333.

Blanke, B., Arhan, M., Madec, G., Roche, S., 1999. Warm water paths in the equatorial Atlantic as diagnosed with a general circulation model. J. Phys. Oceanogr. 29 2753-2768.

Botsford, L.W., Moloney, C.L., Hastings, A., et al., 1994. The influence of spatially and temporally varying oceanographic conditions on meroplanktonic metapopulations. Deep-Sea Res. II 41, 107-145.

Bouffard, J., Vignudelli, S., Herrmann, M., Lyard, F., Marsaleix, P., Menard, Y., Cipollini, P., 2008. Comparison of ocean dynamics with a regional circulation model and improved altimetry in the North-western Mediterranean. Terr. Atmos. Ocean. Sci. 19, 117-133.

Carlotti, F., Wolf, K.U., 1998. A Lagrangian ensemble model of Calanus finmarchicus coupled with a 1-D ecosystem model. Fish. Oceanogr. 7 (3-4), 191-204.

Carr, S.D., Capet, X.J., Mcwilliams, J.C., Pennington, J.T., Chavez, F.P., 2008. The influence of diel vertical migration on zooplankton transport and recruitment in an upwelling region: estimates from a coupled behavioral-physical model. Fish. Oceanogr. 17 (1), 1-15

Champalbert, G., 1996. Characteristics of zooplankton standing stock and communities in the western Mediterranean Sea: relations to hydrology. Sci. Mar. 60 (Suppl. 2), 97-113.

Cianelli, D., Diaz, F., Leredde, Y., Marsaleix, P., Carlotti, F., 2007. Particle exchange and residence times in the North Western Mediterranean. Nuovo Cimento C 30 139-148.

Diaz, F., Raimbault, P., Boudjellal, B., Garcia, N., Moutin, T., 2001. Early phosphorus limitation during spring in the Gulf of Lions. Mar. Ecol., Prog. Ser. 211, 51-62.

Echevin, V., Crepon, M., Mortier, L., 2003. Interaction of a coastal current with a gulf:application to the shelf circulation of the Gulf of Lions in the Mediterranean Sea. J. Phys. Oceanogr. 33, 188-206.

Estournel, C., Broche, P., Marsaleix, P., Devenon, J.L., Auclair, F., Vehil, R., 2001. The Rhone river plume in unsteady conditions: numerical and experimental results. Est. Coast. Shelf Sci. 53, 25-38.

Estournel, C., Durrieu, X., Marsaleix, P., Auclair, F., Julliand, C., Vehil, R., 2003. Observation and modelisation of the winter coastal oceanic circulation in the Gulf of Lions under wind conditions influenced by the continental orography (FETCH experiment). J. Geophys. Res. 108 (C3), 7-1-7-18.

Estournel, C., Auclair, F., Lux, M., Nguyen, C., Marsaleix, P., 2007. "Scale oriented" embedded modeling of the North-Western Mediterranean in the frame of MFSTEP. Ocean Sci. Discuss. 4, 145-187.

Falco, P., Griffa, A., Poulain, P.M., Zambianchi, E., 2000. Transport properties in the Adriatic Sea as deduced from drifter data. J. Phys. Oceanogr. 30, 2055-2071.

Garcia, L.E., Castellon, A., Font, J., Tintore, J., 1996. The Balearic current and volume transports in the Balearic basin. Ocean. Acta 19, 489-497.

Gaspar, P., Gregoris, Y., Lefevre, J.M., 1990. A simple eddy kinetic energy model for simulations of the oceanic vertical mixing: Testsat station Papa and long-term upper ocean study site. J. Geophys. Res. 95, 16179-16193.

Gatti, J., Petrenko, A., Devenon, J.L., Leredde, Y., Ulses, C., 2006. The Rhone river dilution zone present in the northeastern shelf of the Gulf of Lion in Decembe 2003. Continent. Shelf Res. 26, 1794-1805.

Guizien, K., Brochier, T., Duchne, J.C., Koh, B.S., Marsaleix, P., 2006. Dispersal of owenia fusiformis larvae by wind-driven currents: turbulence, swimming behaviour and mortality in a three-dimensional stochastic model. Mar. Ecol., Prog. Ser. 311 $47-66$

Haney, J., 1988. Diel patterns of zooplankton behavior. Bull. Mar. Sci. 43, 583-603.

Hu, Z.Y., Doglioli, A.M., Petrenko, A.A., Marsaleix, P., Dekeyser, I., 2009. Numerical simulations of eddies in the Gulf of Lion. Ocean Model. 28 (4), 203-208.

Lett, C., Veitch, J., van der Lingen, C.D., Hutchings, L., 2007. Assessment of an environmental barrier to transport of ichthyoplankton from the southern to the northern Benguela ecosystems. Mar. Ecol., Prog. Ser. 347, 247-259.

Levy, M., Memery, L., Madec, G., 2000. Combined effects of mesoscale processes and atmospheric high-frequency variability on the spring bloom in the MEDOC area-a mathematical model. Deep-Sea Res. I 47, 27-53.

Mancho, A.M., Hernandez-Garcia, E., Small, D., Wiggins, S., Fernandez, V., 2008 Lagrangian transport through an ocean front in the Northwestern Mediterranean Sea. J. Phys. Oceanogr. 38, 1222-1237.

Mariani, S., Uriz, M.J., Turon, X., Alcoverro, T., 2006. Dispersal strategies in sponge larvae: integrating the life history of larvae and the hydrologic component. Oecologia 149 (1), 174-184.

Mariottini, G.L., Giacco, E., Pane, L., 2008. The mauve stinger Pelagia noctiluca (Forsskål, 1775). Distribution, ecology, toxicity and epidemiology of stings. A review. Mar. Drugs 6 (3), 496-513.

Marsaleix, P., Auclair, F., Floor, J.W., Herrmann, M.J., Estournel, C., Pairaud, I., Ulses, C. 2008. Energy conservation issues in sigma-coordinate free-surface ocean models. Ocean Model. 20 (1), 61-89. 
Mauchline, J., 1998. The biology of calanoid copepods. Adv. Mar. Biol. 33, 710 pp.

Miller, C.B., Lynch, D.R., Carlotti, F., Gentleman, W., Lewis, C.V.W., 1998. Coupling of an individual-based population dynamic model of Calanus finmarchicus to circulation model for the Georges Bank Region. Fish. Oceanogr. 7, 219-234.

Millot, C., Wald, L., 1980. The effect of Mistral wind on the Ligurian current near Provence. Ocean. Acta 3, 399-402.

Millot, C., 1999. Circulation in the Western Mediterranean Sea. J. Mar. Syst. 20, 423-442.

Mullon, C., Freon, P., Parada, C., Van der lingen, C., Huggett, J., 2003. From particles to individuals: modelling the early stages of anchovy (Engraulis capensislencrasicolus) in the southern Benguela. Fish. Oceanogr. 12 (4-5), 396-406.

Oschlies, A., 2002. Nutrient supply to the surface waters of the North Atlantic: model study. J. Geophys. Res. 107 (C5), 3046.

Palomera, I., 1991. Vertical distribution of eggs and larvae of Engraulis encrasicolus in stratified waters of the western Mediterranean. Mar. Biol. 111, 37-44.

Palomera, I., Olivar, M.P., Salat, J., Sabates, A., Coll, M., Garca, A., Morales-Nin, B. 2007. Small pelagic fish in the NW Mediterranean Sea: an ecological review. Progr. Oceanogr. 74 (2-3), 377-396.

Pedrotti, M.L., 1993. Spatial and temporal distribution and recruitment of echinoderm larvae in the Ligurian Sea. J. Mar. Biol. Assoc. U.K. 73, 513-530.

Petrenko, A., 2003. Variability of the circulation features in the Gulf of Lion NW Mediterranean Sea. Importance of inertial currents. Ocean. Acta 26, 323-338.

Petrenko, A., Leredde, Y., Marsaleix, P., 2005. Circulation in a stratified and windforced Gulf of Lions, NW Mediterranean Sea: in-situ and modeling data. Continent. Shelf Res. 25, 7-27.
Petrenko, A., Dufau, C., Estournel, C., 2008. Barotropic eastward currents in the western Gulf of Lion, north-western Mediterranean Sea, during stratified conditions. J. Mar. Syst. 74, 406-428.

Poulain, P.M. 2008. Integration of Lagrangian observations into a Mediterranean Marine Observatory, towards an integrated system of Mediterranean marine observatories. $\mathrm{N}^{\circ}$ 34. In: Briand, F. (Ed.), CIESM Workshop Monographs. Monaco $144 \mathrm{pp}$.

Rubio, A., Taillandier, V., Garreau, P., 2009. Reconstruction of the Mediterranean Northern Current variability and associated cross shelf transports in the Gulf of Lions from satellite tracked drifters and model outputs. J. Mar. Syst. 78 (Suppl. 1), s63-s78.

Sentchev, A., Korotenko, K., 2007. Modelling distribution of flounder larvae in the eastern English Channel: sensitivity to physical forcing and biological behaviour. Mar. Ecol., Prog. Ser. 347, 233-245.

Speirs, D.C., Gurney, W.S.C., Heath, M.R., Horbelt, W., Wood, S.N., Cuevas, B.A., 2006. Ocean-scale modelling of the distribution, abundance, and seasonal dynamics of the copepod Calanus finmarchicus. Mar. Ecol., Prog. Ser. 313, 173-192.

Tugores, M.P., Iglesias, M., Díaz, N., Oñate, D., Miquel, J., Giráldez, A., in press. Latitudinal and interannual distribution of the European anchovy (Engraulis encrasicolus) and sardine (Sardina pilchardus) in the western Mediterranean, and sampling uncertainty in abundance estimates. ICES J. Mar. Sci., doi:10.1093/icesjms/fsq057. 